\title{
5 Societal Readiness
}

In this Spring of 2021, the COVID-19 pandemic is persisting, and the world has entered into the second year of struggle. Present conditions require the study of the dynamics of bottom-up initiatives and define the scope of their reflectivity. Insisting on humanities-led reflectivity helps raise awareness of the importance of framing issues around engaging with science and society, identifying problems, and defining solutions (Pozzo 2019). Possible outcomes of integration of society in science include the aspect of "implementable integration" (Foray 2006). The dimensions of the disaster caused by COVID-19 are becoming clearer day by day. Comparisons with the 2004 tsunami and the 1986 radioactive dust cloud have shown to be insufficient; instead, one looks at the atomic bomb of 1945 and the famines following the economic crisis of 1929. Above all, the perception that nothing will be the same as before in the economy, health management, science, and everyday life has inexorably gained certainty. We are experiencing a paradigm shift, as Thomas Kuhn (1962) first described it: a process that is triggered when the dominant thought, unable to explain numerous anomalies that should not occur, is supplanted by a different thought. The impact of COVID-19 on society is receiving enormous attention from those who are involved in research and innovation. The pandemic is not the first, and it will not be the last of the twenty-first century. Still, already today, we can consider it as the most significant science communication experience in the history of the world. In the media, we are witnessing an explosion of initiatives of citizen science, the science of ordinary citizens, or the science without scientists. We might even say that the pandemic invites us to rethink the indicators of responsible research and innovation (RRI) to redetermine their effectiveness in the interaction between the knowledge of scientists and the experiential knowledge of communities.

In this chapter, I look into the issue pragmatically because I think that in front of a COVID-19 induced fast-changing institutional environment, science and technology studies researchers have some ideas to offer. The pandemic requires social and cultural innovation policies that make communities ready to respond to catastrophic events on their own territory-I consider a case study in Italy's inner areas-through access to data, communities of practice, co-creation, reflection, and inclusion. Finally, COVID-19 ought not to undermine the work done so far to achieve Sustainable Development Goal 1 (Poverty), 3 (Health), 4 (Education), 5 (Gender), 6 (Water), 8 (Work), 10 (Inequalities) and 16 (Peace). Pope Francis has made it clear: "This is the moment to see the poor."

Ә OpenAccess. () 2021 Riccardo Pozzo, published by De Gruyter. (cc) BY-NC-ND This work is licensed under the Creative Commons Attribution-NonCommercial-NoDerivatives 4.0 International License.

https://doi.org/10.1515/9783110709292-006 


\subsection{Experiential Knowledge}

Education, research, and innovation form a triangle that becomes a square if we add the fourth side: society. A few words first on current usages, whereby societal denotes the society as an actor, "societary, e.g., societal change, societal pressure to conform" (OED 1989, s.v.), while social continues to mean the individual socii and what they tend to do, i.e., persons "living together in more or less organized communities; belonging to a community of some kind," and active in social disposition, social engagement, and social life (OED 1989, s.v. 5.b).

Communities stand at many different stages of readiness for implementing programs, and their readiness is a significant factor in determining whether a local program can be effectively carried out and supported within a community (Edwards et al. 2000, 291). In contrast, the government cannot impose any action that induces a community to voluntarily accept new content and processes. In Italian inner areas, e.g., recent surveys have provided qualitative and quantitative data to establish how far communities are ready to remediate to the effects of natural disasters by signing up for additional insurances, taking up new mortgages, and subscribing to further services for utilities (Russo and Scagliarini 2017, 154), which communities did not do in compliance with the law, but voluntarily. We can measure the effectiveness of the exchange between the knowledge of the scientific community and the knowledge of the general public through increasingly precise indicators that range from no-awareness to professionalization-stage after stage-through denial, vague awareness, preplanning, preparation, initiation, stabilization, confirmation, and expansion (Edwards et al. 2000, 298 -300). Today, the COVID-19 pandemic makes it urgent to revisit this dimension of the knowledge economy, highlighting the institutional mechanisms that make it efficient in producing cumulative and reliable knowledge as public goods (Foray 2006).

The Rome Declaration on Responsible Research and Innovation was issued at the end of the Italian Council of the European Union presidential conference on Science, Innovation and Society: Achieving Responsible Research and Innovation in Rome on 22-24 November 2014. It was adopted by the Permanent Representatives Committee on 3 December 2014 and has been gaining recognition since then. The novelty of the Rome Declaration was to point out that:

the continuous engagement of all stakeholders is essential for sustainable, desirable, and acceptable innovation, alongside the four dimensions of economic, social, environmental, 
and institutional sustainability. Hence excellence today is more than ground-breaking discoveries-it includes openness, responsibility, and the co-production of knowledge. ${ }^{56}$

The Rome Declaration lies at the crossroad between the economics of knowledge, the economics of scientific institutions, and knowledge management. Its starting point is Dominique Foray's definition of experiential knowledge: "Experiential knowledge springs from the experience of individuals and organizations. It is not anti-scientific; it merely has not undergone the tests that give a piece of knowledge scientific status. It is nonetheless wide-ranging, sound, rational, and effective in a particular circumstance or life-event" (Foray 2012, 270). Although, as for any other form of knowledge (scientific knowledge, for example), the production and management of experiential knowledge are affected by the presence of externalities (knowledge spillovers in particular), in the domain of experiential knowledge, there are no institutions that as in other domains (i.e., scientific research) enable these externalities to be corrected or their effects to be attenuated. This is why experiential knowledge can be described as fragile despite its centrality and importance (Foray 2012, 270). According to increasingly precise indicators, we can measure the effectiveness of the exchange between the knowledge of the scientific community and the experiential knowledge of the general public. The management of experiential knowledge requires analyzing situations in which this knowledge is crucial to achieving specific objectives and in which devices and mechanisms that are barely visible, explained, or even ignored in the literature are conceived and deployed to attenuate the fragility of this knowledge. Also, we cannot deny the existence of injustice in the distribution of knowledge, education, and communication, which Miranda Fricker (2007) calls epistemic injustice.

In this context, it is helpful to keep in mind that the need for expressions of citizen science implies a connection to the "fragility of experiential knowledge," i. e., the knowledge that-although not scientific-is produced through the experience activity of the laity. It is rational and reliable while remaining fragile. Experiential knowledge-Foray has noted-is local since it arises from particular experiences and applies to very particular contexts. It is fragile since not only are few people who possess it, but as it does not have a comprehensive codification, it is not easy to transmit it, and it disappears when the people who activated it disappear (Foray 2012, 272-273). Foray distinguishes two logics for the mobilization of experiential knowledge within the framework of a scientific ap-

56 https://ec.europa.eu/digital-single-market/en/news/rome-declaration-responsible-researchand-innovation-europe, visited on 6 May 2021. 
proach. On the one hand, the scientific institution realizes that amateurs and laypersons are "in contact" with a particular environment or phenomenon from a unique set of distributed data collection capacities. It is, therefore, up to the scientific institution to organize this collection and then integrate the data while devising an organization facilitating the system's continuity. While this first logic is rather demanding in terms of systematic efforts of collecting and codifying data to be undertaken by the amateurs who therefore have to adapt and share the epistemic culture of science, there is a second superior logic of mobilization of experiential knowledge. The superior logic is undoubtedly to acknowledge that persons "in contact" are not only proper as collectors but have developed experiential knowledge and expertise that is admittedly local and nonscientific but rigorous and rational, enabling them to formulate hypotheses and strategies, test them and thus broaden the variety of possible options for example in terms of treatment of the considered subject (whether an ecosystem or a sick child is involved). This second logic is far more demanding as regards the involvement of both the scientific institution and the amateurs and laypersons that possess any pertinent experiential knowledge (Foray 2012, 275).

It seems, then, that philosophy can be activated to manage and optimize experiential knowledge. Philosophy can foster an integration process in which a scientific institution recognizes the potential value of experiential knowledge as a complement to the scientific knowledge that it produces and implements mechanisms to identify, collect, codify, and use it.

\subsection{Conceptualizing Co-creation}

Historians of philosophy ought to appropriate methodological approaches aimed at integrating processes of co-construction (e.g., agenda-building and policy inputs, co-evaluation, co-funding), processes of co-production (e.g., citizen science), society-sensitive design (e.g., value-sensitive design and gender-sensitive design), science communication (e.g., formal and non-formal processes for improving quality and effectiveness of the interactions between stakeholders), place-based activities combining process and content (e.g., smart cities, living labs, and the regional dimension linked to their smart specialization strategies), creation of spaces for public engagement, including the development and use of temporary and permanent physical spaces (e.g., exhibitions, events) as well as distributed ones (e.g., portals, websites, e-libraries). The processes listed above show the emergence of a new social agent, the so-called prosumer (Helbing 2015, 194), a consumer who becomes involved with designing or customizing products for his/her own needs. Even if there is no doubt that co-creation proc- 
esses already occur, we cannot fully understand their occurrence. Neither can we account for these processes to show how society benefits from the early participation of social agents. As to the co-creation of knowledge, there is still no radical epistemic rethinking: the debates have focused on the joint creation of value by the company and the customer, allowing customers "to co-construct the service experience to suit their context" (Prahalad and Venkatram 2004, 8). Philosophers might be interested in posing the following questions: How is the co-creation of knowledge possible? Why does the co-creation of knowledge bother? These questions are central in co-creation epistemology and have significant effects on benchmarking and the implementation of societal readiness.

Access, participation, and co-creation are preconditions for achieving the integration of science in society. It may not be easy to attract an audience with a different profile from the usual. The issues of access and participation seem to resolve much more about demand than about supply. Scientific competencies are about awareness-raising. At stake is the notion of scientific citizenship (Jasanoff 2004), which consists of the "active and knowledge-driven participation of citizens in the democratic processes, including agenda setting, information gathering, co-creation and evaluation" (Archibugi 2015, 15). For instance, in 2016, the network of the Ciência Viva science centers took part in a pilot program of the Portuguese government to launch a nationwide process of bottom-up participation by ordinary citizens in defining and prioritizing research agendas alongside their local representatives. The initiative Public Participation Labs (Laboratórios de Participação Pública) invited local citizens and municipal authorities to propose ideas for research projects relevant to their regions or cities in spaces of exchange that were hosted at the Ciência Viva science centers to provide neutral environments closer to the local public. ${ }^{57}$

Europe has existed as a cultural, political, and economic identity for centuries, although its nature and coherence have been contested dramatically over time. The following years need a great effort of responsibility and participation. The pandemic invites us to urgently rethink the paradigm of the six keys indicated by the European Commission for RRI, which are: "engagement of citizens, gender equality, formal and non-formal science education, open science, research ethics and research integrity, governance" (Archibugi 2015, 12). Responsible research and innovation is a notion that asks societal actors to work together during the whole research and innovation process to align them with the citizens' values, needs, and hopes. In a nutshell, responsible research and innovation is a cross-cutting topic whose aim is to engage society better. RRI occur

57 https://www.cienciaviva.pt/home/, visited on 6 May 2021. 
where forms of creativity and diversity can be modeled or practiced, where separateness, difference, and specificity can be asserted and maintained in productive ways that enhance the quality of life. The cultural, political, and economic spheres exist in dynamic relation to each other. In sum, to deepen the relationship between science and society, and thus reinforce public confidence in science, it is necessary to foster the engagement of citizens and civil society in research and innovation by promoting science education, by making scientific knowledge more accessible, by developing responsible research and innovation agendas that meet concerns and expectations of citizens and civil society, and by igniting a fruitful and rich dialogue with stakeholders. During the 6th Framework Program, Science and Society was launched to establish a common strategy to better connect science and European citizens. Under the 7th Framework Program, Science and Society became Science in Society with the primary objective of fostering public engagement through a sustained two-way dialogue between science and civil society. With Horizon 2020 (i.e., the 8th Framework Program), responsible research and innovation has become a cross-cutting issue that takes up all appropriate activities. In this context, the program was renamed Science with and for Society and aimed to build effective cooperation between science and society, recruit new talent for science, and pair scientific excellence with social awareness and responsibility (Mejlgaard and Bloch 2012; Mejlgaard et al. 2012; Mejlgaard et al. 2018).

The traditional idea according to which an enlightened entrepreneur will understand market demands and how the exploitation and the combination of technological opportunities will bring into the market a successful product or a process or a service innovation, is more and more outdated when it comes to understanding processes of change in the economy and society. Today, users are more active and very often consulted by producers. Users are not only providing new inputs that manufacturers can use to develop and refine their ideas and products. They can also modify and anticipate, often on a modest scale, the innovations of the future. This provides new opportunities since the number of players that have a say in shaping the transformations of society is more extensive than in the past. While in the previous industrial revolutions most of the innovations were introduced by a restricted number of players (entrepreneurs, scientists, and engineers) which had to face ex-post the success or the failure in the marketplace, in the present time of Industry 4.0, we see a much greater number of active players, which often interact among themselves not only through market transactions but through a large variety of for-profit and non-profit connections.

Nevertheless, only marginally these models have taken into account the actual and potential role that citizens and civil society can take in shaping the in- 
novation process. In recent years, it has become clear that co-creation plays a central role within innovation because a "specific innovation can no longer be seen as the result of predefined and isolated innovation activities but rather as the outcome of a complex co-creation process involving knowledge flows across the entire economic and social environment" (EUR 2016b, 11). These flows warrant the highest interest in monitoring co-creation to integrate society in science and innovation. The success of co-creation is based on the continuous and intensive methodological cooperation of the partners. Hence, research efforts consist of the ongoing evaluation of each project, including the preparation of prototype activities for the exchange between theorists and practitioners. To ensure a consistent and coherent investigation, researchers rely on diverse research methods, from in-depth individual interviews to focus groups, surveys, and online fora.

Unifying the roles of consumers and producers has implications for the production of goods and services and knowledge production. Such a shift also applies to cognitive sciences and the philosophy of the mind. From the viewpoint of ethics, specific human action areas have shown that the lack of involvement of specific social agents leads to unsatisfactory results as regards providing goods, services, and knowledge with related forms of injustice (Fricker 2007; Maschi and Youdin 2012). Finally, the start of open innovation processes (as opposed to traditional closed innovation) and the democratization of science require the participation of all actors, women, and men. In this last direction, two fundamental outcomes are expected: first, the critical reconsideration of the notion of homo oeconomicus; and second, the gender budgeting analysis that discloses how actors within science, research, higher learning institutions, and public management are stifling for gender equality and diversity of science. Gender budgeting has proven to be an effective tool to increase the awareness of gender and diversity in procedures and processes of resource allocation to improve the outcomes for women and men. It is "a gender-based assessment of budgets, incorporating a gender perspective at all levels of the budgetary process, and restructuring revenues and expenditures to promote gender equality" (Council of Europe 2005, 10).

\subsection{Preparedness and Readiness}

Emergency management puts the usual division of roles and responsibilities under stress. Public officials must have precise knowledge of the specific normative framework in which they operate, specific mandates and associated role responsibilities, and the special normative tools contemplated by the system to 
deal with emergencies. It is up to local administrators to raise risk awareness, despite the different perceptions that citizens have of risk immediacy and the different conditions for involving stakeholders. The definition of an action protocol in emergency conditions is not sufficient to ensure the effectiveness of the action. There is also a need for practices that mobilize the intervention of individual employees of public administrations who are coping with conditions in which chains of command and purely hierarchical-organizational relationships might be interrupted or with skills that would no longer be available in ordinary conditions. Municipalities that had already developed an emergency plan (in the wake of natural disasters) have proven to be more ready and effective in dealing with the specific risk conditions of the pandemic (Pagliacci and Russo 2019a).

The uneven geographic distribution of COVID-19 remains an enigma in Italy, given the intense flow of movements between regions before the isolation measures. We are facing irregular patterns of geographical distribution. However, the data collected so far indicate that air pollution in the various regions (e.g., the fine dust in Lombardy) determines causal links that have significant implications for the virus spread (Becchetti et al. 2020).

A community can be more or less resilient. Its resilience improves if a proper assessment is made of hazards and vulnerabilities. The analysis of local exposures suggests that communities are to look out for spatially linked risks. ${ }^{58}$ Socio-economic research can elaborate analytical insights into specific and geographically defined risks using data with different spatial granularity produced by various official sources to allow their use in combination with data on exposure and vulnerability (Pagliacci and Russo 2019b).

In Italy, epidemiological data about COVID-19 are collected daily by the regional institutions that send them to the Italian Ministry of Health. The Italian Ministry of Health, in turn, sends the data to the Italian Civil Protection Department (Morettini et al. 2020), which is the government agency entrusted with driving rapid response and informed decision-making during emergencies. Thanks to the accurate and quick availability of data, Italian central and local administrations can provide careful assessments of the pandemic's severity, spread, and impact on implementing efficient and effective response strategies. The same can be shown for many countries beyond Italy, as the Research Data Alliance has documented. ${ }^{59}$

58 https://www.undrr.org, visited on 6 May 2021.

59 RDA COVID-19 Working Group. Recommendations and Guidelines on data sharing. Research Data Alliance, 2020. DOI: https://doi.org/10.15497/rda00052. 
In Italy, the requirement for timely and accurate collection, reporting, and sharing of data within and among research communities, public health practitioners, clinicians, and policymakers has been met effectively. The issue is now building processes that can create a lasting coalition around the goals needed to reduce vulnerability. Dedicated to social and material vulnerability and resilience of communities exposed to natural hazards is Italy's REDI consortium (an acronym for Reducing Risks of Natural Disasters), which has its seat at the University of Camerino and which also includes the National Institute of Nuclear Physics, the National Institute of Geophysics and Volcanology and the Gran Sasso Science Institute. REDI is a research, innovation, and training center. Its mission is to contribute to the development of interdisciplinary research for improving preparedness and readiness to respond to disasters by communities, decreasing their recovery and recovery times. It is currently carrying out projects on requalified built environment, community resilience as well as on risk awareness, education, training, and engagement for disaster risk reduction for communities struggling to recover from natural disasters. ${ }^{60}$ Finally, a public debate on lessons learned from the first phases of COVID-19 management is currently taking place in Italy because the perception of a lack of coordination has emerged between political and scientific levels, institutional claim-makers, and the media (Ruiu 2020).

Returning to COVID-19 and taking territory as a reference (region, metropolitan city, province, internal area), today we know that in order to comply with social distancing precautions and be effective with positive case tracking local administrations must equip themselves with management infrastructures that were unimaginable before the pandemic. The reference definition for community preparedness in the face of epidemiological risks was proposed by the United States Centers for Disease Control and Prevention in 2018 and updated in January 2019. Community preparedness is the ability of communities to prepare for, withstand, and recover from public health incidents in both the short and long term:

Administrations at national, regional, and municipal levels, as well as local and territorial stakeholders, are responsible for preparing communities to do their part in support the development of public health, health care, human services, mental/behavioral health, and environmental health systems that support the community preparedness. Communities need to be made aware of preventing, responding to, and recovering from incidents that adversely affect public health. ${ }^{61}$

60 http://www.redi-research.eu/it/homepage, visited on 6 May 2021.

61 https://www.cdc.gov/cpr/readiness/capabilities.htm, visited on 6 May 2021. 
At this juncture, one of the tasks that researchers in science and technology studies can take upon themselves is precisely to verify the interplay of the proposed management solutions with existing societal readiness levels (SRL). It has become clear that the assessment of technology readiness levels (TRL) ${ }^{62}$ ought to be accompanied by that of the corresponding SRL. The SRL have been developed at Denmark's Innovation Fund. They are meant for assessing "the level of societal adaptation of, for instance, a particular social project, a technology, a product, a process, an intervention, or an innovation to be integrated into society." 63 The lower the social adaptation, the better the transition plan is expected to be. SRL 1 is the lowest, and SRL 9 is the highest level:

\section{SRL 1-identifying problem and identifying societal readiness}

SRL 2-formulation of problem, proposed solution(s) and potential impact, expected societal readiness; identifying relevant stakeholders for the project

SRL 3-initial testing of proposed solution(s) together with relevant stakeholders

SRL 4-problem validated through pilot testing in relevant environment to substantiate proposed impact and societal readiness

SRL 5-proposed solution(s) validated, now by relevant stakeholders in the area

SRL 6-solution(s) demonstrated in relevant environment and in cooperation with relevant stakeholders to gain initial feedback on potential impact

SRL 7-refinement of project and/or solution and, if needed, retesting in relevant environment with relevant stakeholders

SRL 8-proposed solution(s) as well as a plan for societal adaptation complete and qualified

SRL 9-actual project solution(s) proven in relevant environment. ${ }^{64}$

Community readiness is about fostering epistemic responsibility. Its effectiveness can be measured in terms of community engagement and accountability relationships. At the local level, the availability of correct information to people with relevant competencies and skills at the right time and in the correct form is crucial in coping with emergencies. Typically, conflicts arise about whether, how, and when to distribute information. In this respect, Italian inner areas have faced critical situations. It has been shown that a proper assessment of local hazards and vulnerabilities can enhance community resilience (Pagliacci and Russo 2019a).

62 https://www.iso.org/standard/56064.html, visited on 6 May 2021.

63 https://innovationsfonden.dk/sites/default/files/2019-03/societal_readiness_levels_-_srl. pdf, visited on 6 May 2021.

64 https://innovationsfonden.dk/sites/default/files/2019-03/societal_readiness_levels_-_srl. pdf visited on 6 May 2021. 
At the European level, Pan-European Privacy-Preserving Proximity Tracing (PEPP-PT) and Decentralized Privacy-Preserving Proximity Tracing (DP3T) have become an issue. Both the European Parliament and the European Commission have adopted a firm position on safeguarding privacy in the fight against COVID19. According to an SWG survey published on 31 March 2020 in the Corriere della Sera-at the climax of the COVID-19 spread in Italy-it appears that: (i) $63 \%$ of Italians agree that the state can control the movements of citizens even without their consent; (ii) $64 \%$ agree on the hypothesis of putting the electronic bracelet on people who are in quarantine; (iii) $67 \%$ accept that mobile phones are used to check whether or not people are complying with the bans; and finally (iv) $74 \%$ have nothing to object to the use of drones to control the movement of people on the street (Arachi 2020, 22).

As the COVID-19 emergency increases, the need for transparency grows (Pozzo and Virgili 2020). If societal readiness for a determinate technical or social solution remains low, measures should induce a natural transition towards social adaptation. In the case of natural disasters, and such is the COVID-19 pandemic, at issue is how to set into motion social and cultural innovation processes that prepare communities ${ }^{65}$ through access to data, participation in communities of practice, co-creation, reflection, and inclusion (Esposito et al. 2017; Pozzo et al. 2020).

The overall challenge lies in fostering participation and strengthening practical modes of co-creation. Some people do not want to share their knowledge, e.g., on transportation or urban planning issues, making place-based formal and informal education activities at science centers a part of their solution. The analysis of (self)exclusion requires a qualitative methodology based on a multiplecase-study approach. It is necessary to consider carrying out pilot research through Delphic interviews with experts and professional staff of science centers, museums, and festivals who routinely work with audiences-the need for longitudinal investigation and the lack of primary empirical data are the main reasons for using this methodology. Particularly interesting exploratory contexts highlight new phenomena, heuristics, emergence trends, or weak signals, which a more quantitative approach does not disclose. Interviewers extract informed opinions about the essential identification and specificity of (self)excluded individuals and groups and the causes of (self)exclusion (National Endowment for the Arts 2014). Many local actors are involved in the process from the very beginning. As regards devising research tools that ensure access and research penetration of (self)excluded groups, it is essential to engage representatives of the iden-

65 https://www.undrr.org, visited on 6 May 2021. 
tified (self)excluded groups to gather data enabling the deepened identification of the causes of (self)exclusion from co-creation. Local partnerships reflect the social environment and the specific cultural character of the territories. Simultaneously, the consultation and research processes serve to develop initial models of activities to be prototyped. Activities are strictly combined with indicators on possibly unknown access thresholds and limits in readiness of target groups to be involved in co-creation activities and science capital levels. The process must be repeated many times until a final activity scenario is delivered. The redesigning process is combined with research on change as regards the readiness to engage, ways and possibilities to gain new knowledge, and the ability to share knowledge and experience with others.

One might conclude that experts and institutions specializing in science communication like science centers and museums as well as science festivals and place-based public engagement activities (science parliaments, hackathons, innovation labs) are particularly well-suited to put the responsible research and innovation public engagement agenda into practice at the regional and local level, for they are the ones that are reaching out best to non-traditional research and innovation actors in the framework of several configurations of place-based activities, experiences, and gatherings. These institutions provide interfaces between civil society and research, whose potential is still underdeveloped, which is proven by three reasons. First, they already have several participants in their everyday programs. Second, they have the ability and experience to encourage new groups and involve them in cooperation. Third, they look for new ways of engaging actors who have not attended any of their programs yet. This has led to a broader understanding of the process of knowledge generation and has shown how an innovation that is based on scientific and technological advances can be successful or unsuccessful, not only economically but also according to its capability to integrate with other social, organizational, and cultural innovations.

In sum, the striking feature of societal readiness assessments lies in their being designed and tested in a co-creation process, which requires step after step to conceptualize the needs, identify specific targets, design the activity, prototype it, test it with a controlled target group, and release it to open groups, always under strict ongoing evaluation and co-evaluation with the involvement of users. Last but not least, the replication of the prototypes by new actors to be reached out through appropriate communication and dissemination strategies in order for them to implement the prototypes and the methodological research locally fosters a cascade effect of the activities for the benefit of the community. 


\subsection{Society-sensitive Design}

Co-construction and society-sensitive design are well-intentioned, but research ought to consider how they are refracted through practicalities embedded in existing institutions and interests. This has been documented extensively for ICT. There is a structural element here, in the sense that co-construction and design necessarily occur at an early stage. Simultaneously, there are many other factors and circumstances at play in the later stages that co-determine outcomes. Drawing on these practices and analyzing the bias on the production of goods or services, it is possible to reframe the process of creating new knowledge in a participative way. We might start from the presupposition that mono-stakeholder alliances belong to the past. Instead, the focus is on local partnerships that connect research and innovation with citizens and possibly diverse civil society actors (e.g., municipalities, local stakeholders, representatives from industry, creative economy, non-governmental organizations, etc.). In fact, "society can now work with and for science as much as science is working with and for society" (EUR 2016a, 8). Not surprisingly, the Horizon Prizes of the European Innovation Council call for projects that demonstrate the feasibility or potential of particular technologies and promote their acceptance in society. ${ }^{66}$

The United Nations is calling for a global effort to tackle the pandemic crisis, "which risks erasing decades of progress in the fight against poverty and exacerbating the already high levels of inequality in and between countries." ${ }^{67}$ Local administrations are the first to work on societal readiness and reduce inequalities, which is also the exhortation of Pope Francis:

\footnotetext{
The coronavirus disease 2019 pandemic has illuminated inequities that have put poor people-in both low-income nations and in rich countries-at the greatest risk of suffering. Pope Francis recently pointed to that in an interview: "This is the moment to see the poor.” (Von Braun et al. 2020, 214)
}

Working on participatory approaches fueled by social and cultural innovation processes related to accessing data, creating communities of practices, establishing the boundaries of group use (Floridi 2014) while fostering individual processes of reflection and collective processes of inclusion (Pozzo et al. 2020) can boost community readiness for local COVID-19 management.

66 https://ec.europa.eu/research/eic/index.cfm?pg=prizes, visited on 6 May 2021.

67 United Nations Sustainable Development Solutions Network (2020): UN working to fight Covid-19 and achieve Global Goals. https://www.unsdsn.org/, visited on 6 May 2021. 
History of philosophy has a say because fragile knowledge has become relevant for actors specializing in science communication who concentrate on strengthening the perception of visitors or event participants that science and research are a crucial and inseparable part of modern society. In this process, science centers aim at enhancing fragile knowledge in specific areas while igniting a constructive dialogue between civil society and research. However, sharing fragile knowledge, e.g., on public health issues, can be problematic. Some people can be not confident enough or feel intimidated by the presence of experts. This can be remediated by providing proper conditions for knowledge and experience exchange. For this reason, it is necessary to develop a better understanding of co-creation processes and outcomes under various cultural, societal, and regulatory backgrounds, which allows better-targeted policy support in the future. The key notion is co-creation, which is the indicator for measuring cultural innovation, thus providing an effective new basis for benchmarking and comparisons. 